\title{
Relationship between Purchase Intentions for Luxury Brands and Customer Experience - Comparative Verification among Product Categories and Brand Ranks
}

\author{
Kazutoshi Fujiwara ${ }^{1,2}$, Shin'ya Nagasawa ${ }^{1}$ \\ ${ }^{1}$ Graduate School of Commerce, Waseda University, Tokyo, Japan \\ ${ }^{2}$ International Operations Division, Kikkoman Corporation, Tokyo, Japan \\ Email address: \\ k-fujiwara@toki.waseda.jp (Kazutoshi Fujiwara), nagasawa@waseda.jp (Shin’ya Nagasawa)
}

\section{To cite this article:}

Kazutoshi Fujiwara, Shin'ya Nagasawa. Relationship between Purchase Intentions for Luxury Brands and Customer Experience Comparative Verification Among Product Categories and Brand Ranks. Science Journal of Business and Management. Special Issue: Customer Experience Management / Marketing Branding. Vol. 3, No. 2-1, 2015, pp. 1-10. doi: 10.11648/j.sjbm.s.2015030201.11

\begin{abstract}
This paper aims to provide empirically validated evidence on the effect that experiences, which was proposed by Schmitt [1], have on purchase intentions. For this study, I chose GODIVA, Meiji, Ferrari, and Toyota as subject luxury brands and conducted comparative analyses between product categories (food and cars) and brand ranks (luxury brands [Note 1] and mass brands). The results suggested the following: 1) Providing customers with satisfaction through the five senses and positive feelings by taking advantage of advertisements, products, and store designs is something a brand must achieve at the very least, regardless of brand rank, for the product categories of food and cars, and providing this value alone will not be enough for luxury brands to distinguish themselves from mass brands. 2) Both food and car luxury brands make an attempt to distinguish themselves from mass brands by producing emotions that will make consumers want to have an active connection with other consumers or voluntarily recommend the brand to others. 3) Conspicuousness, which has been believed to be a typical motive for the consumption of luxury brands since the 19th century, does not necessarily apply today.
\end{abstract}

Keywords: Luxury Brand, Customer Experience

\section{Introduction}

The idea of Japan being a major consumer of luxury brands is probably common knowledge. Saito [2] states that Japan has the largest luxury market in the world even when measured according to macroeconomic factors such as population and average income. In fact, the streets of prime locations in Tokyo are lined with luxury shops, and people dressed from head to toe in brand name products walking leisurely down the street has become part of the scenery.

LVMH Moët Hennessy Louis Vuitton (hereinafter referred to as LVMH) --which controls over 60 subsidiary brands including Louis Vuitton, BVLGARI, and Christian Dior, and has been called the world's largest brand empire-- has remarked that Japan has an extremely important market [3]. LVMH's percentage of sales in Japan for FY2013 was 7\%. This figure trailed the United States (23\%) and France (11\%) [3], but it does not include purchases made overseas by Japanese people. Therefore, it is possible that Japan's market share is actually much larger.
Such trends are by no means limited to the product categories of clothes, leather products, watches, and jewelry-categories LVMH plays a major role in. GODIVA, the Belgian luxury chocolate brand, has expanded its business to over 80 countries around the world, and their percentage of sales in Japan has reached $32 \%$ [4]. It is clear that the brand consciousness of Japanese people covers a wide range of product categories.

However, much of the previous studies on luxury brands placed an overemphasis on the product categories of clothing and leather products [5]. Furthermore, when asked to name luxury brands that come to mind, consumers are only able to come up with brands such as Louis Vuitton, Chanel, ROLEX, Ferrari, and The Ritz-Carlton [6]. Thus, I have the impression that, in general, few people think of brands in the food category such as GODIVA as luxury brands.

Therefore, the objective of this paper is to demonstrate that luxury brand strategies can be applied to a broader range of product categories than people realize by examining GODIVA, which is a luxury food brand, and performing empirical 
analyses that place an emphasis on consumer perception. This paper will also shed light on how GODIVA has gained its status as a luxury brand and in what aspects the company has attempted to distinguish itself from mass brands.

As for the organization of this paper, I will first go over past studies on consumer behavior concerning luxury brands and provide the definition of luxury as it pertains to this paper. Next, I will provide an explanation on the selection of the subject brands as well as five experience types (which is the analytical viewpoint I will use). I will also present the scale that I will use for the questionnaires. I will then form a hypothesis concerning the relationship between purchase intention and the five experience types for each subject brand, and perform a multiple regression analysis. Finally, I will perform a comparative analysis of the results and draw conclusions.

\section{Previous Studies}

\subsection{Theoretical Studies on Consumer Behavior}

During the dawn of the era for research on consumer behavior towards luxury brands, Rae [7] stated that the consumption of luxury brands was attributable to conspicuousness and that a sense of rarity, the high price tag, and boasting were contributing factors for this. Veblen [8], an American economist and sociologist, expressed a similar view in his book The Theory of the Leisure Class. He made a critical assessment that people of the leisure class purchased luxury brands for competitive reasons: to show off. Such studies paved the way for later studies, as many researchers have conducted studies on the concept of motives for purchasing luxury brands ever since.

Leibenstein [9] called the effect proposed by Veblen [8], in which purchase motives result from conspicuousness, the "Veblenian Effect," naming it after Veblen. Moreover, he called the effect that is related to group conformity, in which the effectiveness of a brand increases as the number of people in a reference group who own the brand increase, the Bandwagon Effect. In addition, he called the effect that is related to individuality, in which the effectiveness of a brand decreases as the number of people who own the brand increase, the Snob Effect. These three effects demonstrate that it is not just personal factors that affect the motives for purchasing luxury brands (e.g. consuming or using a product), but rather social factors which are based on public self-consciousness --how owning brands is perceived by others-- have an effect on the consumption of luxury brands.

Vigneron and Johnson [10], in consideration of past studies, point out that in addition to the aforementioned social factors, personal matters such as emotional value and qualitative value, which are based on private self-consciousness caused by one's internal emotions, are also factors. Table 1 is a summary of studies on the purchase motives of luxury brands up to this point. Moreover, as it is shown in Table 2, consumer behavior, according to purchase motive, is categorized into four types along two axes: "Self-consciousness" and "Importance of the
Perception of Price as Indicator of Prestige."

These studies demonstrate that motives for the consumption of luxury brands, which has been believed to be conspicuousness since the 19th century, are affected by a variety of complex factors.

Table 1. Values of Prestige Combined with Relevant Motivations

\begin{tabular}{ll}
\hline VALUE & MOTIVATIONS \\
\hline Conspicuous & Veblenian \\
Unique & Snob \\
Social & Bandwagon \\
Emotional & Hedonist \\
Quality & Perfectionist \\
\hline
\end{tabular}

Source: Vigneron and Johnson[10]

Table 2. Prestige-Seeking Consumer Behaviors

\begin{tabular}{ccc}
\hline $\begin{array}{c}\text { Private } \\
\uparrow \\
\text { Self-consciousness }\end{array}$ & $\begin{array}{c}\text { Hedonist } \\
\text { Perfectionist }\end{array}$ \\
$\begin{array}{c}\text { Bublic } \\
\text { Pundwagon } \quad \text { Snob }\end{array}$ & Veblenian \\
& Lower & $\begin{array}{c}\text { Importance of The } \\
\text { Perception } \\
\text { of Price as Indicator } \\
\text { of Prestige }\end{array}$ \\
\hline
\end{tabular}

Source: Vigneron and Johnson[10]

\subsection{Empirical studies on Consumer Behavior}

As Terasaki [11] points out, few empirical studies have been conducted on luxury brands. Among them, the study conducted by Kapfere [12], in which he collected data on the perceived values of luxury brands, is a well-known empirical study. In the study, Kapfere performed a cluster analysis and collected data on "Authenticity of the Experience," "Creative Niche Luxury," "Safe Values and Prestige," and "Outstanding Badges" as perceived values of luxury brands [Note 2].

In his study, Terasaki [11] performed a comparative analysis on luxury fashion brands and luxury mechanical clock brands after pointing out that the luxury brands that the participants of the study had in mind was not known and that there were question marks concerning probability. Through the comparative analysis, he collected data on "Outstanding Badges" and "Authenticity of the Experience" for both product categories. He also collected data on "Creative and Advanced" and "Safe Values and Prestige" for luxury fashion brands and "Sense of Exclusiveness and Specialness" and "Traditional Craftsman-like Qualities" for luxury mechanical clock brands as distinct elements.

The study demonstrated empirically that perceived values that require particular attention vary depending on the product category.

\subsection{Strategies for Luxury Brands Today}

Traditionally, luxury brands were exclusive products made for select groups of people in the wealthy class. However, they have undergone changes over the past 50 years along with the 
popularization of luxury products [13]. Catry [14] points out that this trend is most important in considering luxury brand strategies today and that companies that have enjoyed success in the ever growing luxury market resolve the dilemma of the balance between providing a sense of rarity and sustaining sales by creating an "illusion of scarcity.".

In other words, even if a company sells products which are made from scarce resources, there will be a limit on the sales total. However, sales can still be increased while still sustaining a sense of rarity without losing its status as a luxury brand by strategically controlling prices or distribution or by promoting traditions which fascinate consumers or starting trends.

The sense of rarity that is achieved through such methods is called "information-based rarity." As an example of this concept, the method used by Ferrari, which has intentionally cut down on the number of cars sold while raising the prices of new car models each year, is presented [14]. In fact, Ferrari, for the FY2013 account settlement, despite seeing a 5.4\% decrease from the previous year in the number of cars sold, saw a record high in sales, as sales increased by $5 \%$ from the previous year [15]. Such results were definitely attributable to the adoption of a style of management that emphasized information-based rarity. Several luxury brands which have enjoyed steady growth while also sustaining information-based rarity through activities such as selling exclusive products or by managing stores directly, come to mind.

Based on these things, it is clear that the concept of "information-based rarity" is a vital component in developing luxury brand strategies particularly in the modern age.

Therefore, in this paper, luxury brand is defined as "brands that have earned customer loyalty by managing information-based rarity while also maintaining premium prices."

\section{Problem Areas with Previous Studies and the Objectives of this Paper}

In the previous chapter, by reviewing previous studies, I presented the various motives for the consumption of luxury brands, perceived values, and the characteristics of today's luxury brand strategies. I also brought up problems areas with the previous studies, such as overemphasis of studies on product categories including clothing and leather and the limited number of empirical studies.

In considering the success of GODIVA in the Japanese market, it can be argued that luxury brand strategies, to begin with can be applied to a wide range of product categories, including food. Although the term luxury has been defined by many researchers in the past, none of them, as far as I know, have stated that their definitions should be applied to particular product categories. But I have the impression that the general understanding of the definition's realm of application is much narrower than it actually is.

Therefore, this paper is an empirical study that focuses on luxury food brands, a category that has never been examined before. I will also examine luxury car brands, which have the exact opposite characteristics of food brands, based on certain selection criteria, which I will explain later. Furthermore, in order to clearly demonstrate the characteristics of luxury brands, I will examine mass brands in the categories of food and cars, and perform a comparative analysis on four brands.

By using these methods, I will demonstrate that strategies for luxury brands can be applied to the category of food, just as they can be applied to cars. I will also clarify the commonalities between the two product categories as well as the distinct traits of each. Furthermore, by comparing the luxury brands with mass brands, I will aim to demonstrate the aspects in which the brands have attempted to distinguish themselves from mass brands to allow them to gain their status as luxury brands.

\section{Validation Methods}

I will now explain the selection method for the subject brands, the analytical viewpoints, and my methods for analyzing the data, all of which I will use for this empirical study.

\subsection{Overview of the Surveys}

Table 3. Survey Overview

\begin{tabular}{ll}
\hline Research Agency & Rakuten Research, Inc. \\
\hline Research Method & Internet \\
Delivery Destination & Japan \\
Date & From 8th August to 21 August, 2014 \\
Age & People in their thirties and forties \\
& Household Income is more than 10 million \\
Essential Requisite & yen or household assets (financial assets \\
& and real estate) is more than 50 million \\
& yen \\
& The people who \\
& - choosed the same choices at more than \\
& $90 \%$ questions \\
Elimination Condition & - finished the survey less than 50\% speed \\
& than average speed. \\
& - choosed incorrect answer at trap \\
All Mail Sender & questions. \\
Finally Collected Samples & 5,623 samples (men3,029, women2,594) \\
\hline
\end{tabular}

Since this is a study on luxury brands, I felt that having consumers with certain amount of wealth comment on the brands would be the ideal method. For this reason, I conducted a questionnaire targeting households with an incom of 10 million yen or more or assets of 50 million yen (financial assets and real estate). Furthermore, in order to make the results as accurate as possible, I ruled out all answers of participants that fit the following description: answers answered in less time than the average amount of time it took for the participants of the questionnaire to answer them, answers in which $90 \%$ or more of the answer choices were the same, and answers with wrong choices for trick questions [Note 3]. In the end, I collected 500 sample questionnaires which met all of the criteria (250 males and 250 females) and 
analyzed them. An overview of the surveys is shown in Table 3.

\subsection{Selection of Subject Brands}

In this paper, I will examine the aforementioned GODIVA as a subject luxury food brand. Since expanding their business to Japan in 1972 with Kataoka \& Co., Ltd. as its sales agent [16], GODIVA has actively opened new shops in department stores and prime locations [17]. Then on June 27, 2014, GODIVA announced that in an aim to enhance the brand's image, it would end its domestic sales contract with Kataoka \& Co., Ltd as of March 2015 and that it would place all Japanese shops under their direct control [16, 18]. In addition to producing a sense of rarity through such a system of distribution management, GODIVA has been able to sustain steady growth while also maintaining premium prices [18]. These things are consistent with the definition of luxury brand for this paper.

Furthermore, in order to make the comparative analyses as detailed as possible, I examined product categories other than food by using an FCB grid, which was proposed by Vaughn [19] (Table 4). In the FCB grid, the words "High Involvement" and "Low Involvement" are written along the vertical axis and the words "Thinking" and "Feeling" are written along the horizontal axis and products are divided into four categories. What this grid says is that a style of communication with consumers that is suitable for the characteristics of each product category should be used. In the grid, luxury food --the category GODIVA belongs to-- falls under Quadrant 4 (Low Involvement / Feeling). In order to demonstrate the broad realm of application of luxury brand strategies, which is one of the objectives of this paper, products with very different characteristics should be chosen for comparative purposes. Therefore, I chose cars, which falls under Quadrant 2 (High Involvement / Thinking), which is the exact opposite of Quadrant 4.

I chose Ferrari as a luxury car brand. As I mentioned earlier, Ferrari has earned customer loyalty by producing information-based rarity through the management of prices and distribution. Such achievements, just as in the case of GODIVA, are consistent with the definition of luxury brand for this paper.

Furthermore, in order to compare different ranks in the analyses, I added Meiji and Toyota to the study because they are mass brands that belong to the same product categories as
GODIVA and Ferrari. As for why I chose those two mass brands, they had the top market share (based on monetary value) in FY2012 for Japan's chocolate and car markets [20]. In addition, Meiji is a popular mass brand of chocolate in Japan. A summary of the four subject brands I chose based on this method is shown in Table 5. By using this selection method, a comparative analysis can be made between product categories and between brand ranks.

Table 4. FCB Grid

\begin{tabular}{|c|c|c|}
\hline & Thinking & Feeling \\
\hline \multirow{3}{*}{$\begin{array}{l}\text { High } \\
\text { Involvement }\end{array}$} & 1.Informative & 2.Affective \\
\hline & Example: & Example: \\
\hline & Car $\cdot$ House $\cdot$ Furnishings & Jewely $\cdot$ Cosmetics $\cdot$ Fashion \\
\hline \multirow{3}{*}{$\begin{array}{l}\text { Low } \\
\text { Involvement }\end{array}$} & 3.Habit Formation & 4.Self-Satisfaction \\
\hline & Example: & Example: \\
\hline & Food $\cdot$ Household Items & Cigarettes $\cdot$ Luquor $\cdot$ Candy \\
\hline
\end{tabular}

Source: Vaughn [19] (Excerpt)

Table 5. Positioning of Survey Subjects

\begin{tabular}{llll}
\hline & & Brand Rank \\
\cline { 3 - 4 } & & Luxury & Mass \\
\hline Product & Food & GODIVA & MEIJI \\
Category & Car & FERRARI & TOYOTA \\
\hline
\end{tabular}

\subsection{Measurements using the Strategic Experiential Module}

I don't believe that factors which contribute to the success of luxury brands can be discussed by looking only at the functions and benefits of products and services, which are emphasized in traditional marketing strategies. Positive emotions, such as inspiration and excitement that consumers experience by using the products or services must be considered. Schmitt [1] refers to such emotions as experiences, and presents the Strategic Experiential Module (hereinafter referred to as SEM), which can be utilized in marketing activities. SEMs categorize the components of experiences into five types: Sense, Feel, Think, Act, and Relate.

Table 6 is a questionnaire form I created based on Schmitt [1]'s SEM to measure experiences. The letter " $X$ " in the questionnaire items shown in Table 6 will be replaced with GODIVA chocolates, Meiji chocolates, Ferrari cars, and Toyota cars. The questions are to be answered on a scale of 1 (I strongly disagree) to 7 (I strongly agree).

Table 6. Questionnaire Form for Measuring SEM

\begin{tabular}{lll}
\hline Customer Experience & \multicolumn{2}{l}{ Questionnaire Item } \\
SENSE & Q1 & I think X looks good \\
& Q2 & I think X makes me feel good through my own five sense \\
& Q3 & I think X makes me feel excited through my own five sense \\
FEEL & Q4 & I feel warmth in X \\
& Q5 & I feel the excitement in the X \\
& Q6 & I feel pleasure in X \\
THINK & Q7 & X has the history \\
& Q8 & X piques my intellectual curiosity \\
ACT & Q10 & X has provocative implications \\
\hline
\end{tabular}




\begin{tabular}{lll}
\hline Customer Experience & \multicolumn{2}{l}{ Questionnaire Item } \\
\hline & Q11 & If I join the event for new products of X, I want to say somebody about that \\
& Q12 & X can change my lifestyle \\
RELATE & Q13 & I want to join the fan club of X, and interact with the members \\
& Q14 & I want to present X to somebody \\
\hline
\end{tabular}

Source: The autor used JSA Schmitt [1] as a reference

\subsection{The Multiple Regression Model Equation}

I will ask questions on the purchase intentions (hereinafter referred to as PI) of four subject brands on a scale of 1 (I strongly disagree) to 7 (I strongly agree). These will be the explained variables. I will then assign $\mathrm{X}_{\mathrm{S}}, \mathrm{X}_{\mathrm{F}}, \mathrm{X}_{\mathrm{T}}, \mathrm{X}_{\mathrm{A}}$, and $\mathrm{X}_{\mathrm{R}}$ in order as synthetic variable-- the sum of each of the answers (3 categories each) for the five experience types of Sense, Feel, Think, Act, and Relate, which I obtained from the SEM measurement questionnaires shown in Table 6 . These will be the explanatory variables. Next, I will assign $\beta_{\mathrm{S}}, \beta_{\mathrm{F}}, \beta_{\mathrm{T}}, \beta_{\mathrm{A}}$, and $\beta_{\mathrm{R}}$ in order as standard partial regression coefficients for the explanatory variables. Assuming that $\beta_{0}$ is the constant term, the following multiple regression model equation will result. I will conduct a multiple regression analysis by using the following formula (1).
$\mathrm{PI}=\beta_{\mathrm{S}} \cdot \mathrm{X}_{\mathrm{S}}+\beta_{\mathrm{F}} \cdot \mathrm{X}_{\mathrm{F}}+\beta_{\mathrm{T}} \cdot \mathrm{X}_{\mathrm{T}}+\beta_{\mathrm{A}} \cdot \mathrm{X}_{\mathrm{A}}+\beta_{\mathrm{R}} \cdot \mathrm{X}_{\mathrm{R}}+\beta_{0}(1)$

\section{Hypothesis}

Table 7 is a summary of the purposes of experiential marketing, which I wrote by referring to Schmitt's [1] study. For this study, when coming up with a hypothesis for the five experience types of Sense, Feel, Think, Act, and Relate, if the purposes described in Table 7 are achieved, the standard partial regression coefficients of $\beta_{\mathrm{S}}, \beta_{\mathrm{F}}, \beta_{\mathrm{T}}, \beta_{\mathrm{A}}$, and $\beta_{\mathrm{R}}$ indicate significant positive correlations. This will mean that each of the above experience types will have a direct positive effect on the purchase intentions of consumers for the subject brands.

Table 7. Purpose of Experiential Marketing

\begin{tabular}{ll}
\hline Experiential Marketing & Purpose \\
\hline SENSE Marketing & $\begin{array}{l}\text { Providing consumers with an aesthetic sense of joy and excitement by stimulating the five senses: sight, } \\
\text { hearing, smell, taste, and touch. } \\
\text { Getting consumers to have an emotional attachment towards the brand through the use of Experience } \\
\text { Providers such as advertisements and product designs. } \\
\text { Getting consumers to reevaluate the company or products by stimulating the creative ideas of consumers } \\
\text { after gaining an understanding of the knowledge structure of consumers as well as what catches their } \\
\text { attention or focus. } \\
\text { Getting consumers to want to express themselves to others by taking advantage of the lifestyles of the } \\
\text { consumers. } \\
\text { Getting consumers to want to make connections with other consumers by building a community or getting } \\
\text { consumers to think of brands as the backbone of social organizations so that they will voluntarily recommend } \\
\text { the brand to others. }\end{array}$ \\
\hline
\end{tabular}

Source: The author used Schmitt [1] as a reference

\subsection{Hypothesis of Sense}

The purpose of Sense marketing, as it is described in Table 7 , is to provide consumers with an aesthetic sense of joy and excitement through the five senses: sight, hearing, smell, taste, and touch.

There is no doubt that GODIVA has been able to provide the basic benefit that food provides of satisfying the sense of taste. They also provide additional elements of satisfaction, as various elements appeal to our sense of sight. Such examples include the appearance of the store (the gold color that is used throughout the shop, which gives the shop a polished look); the shop layout which produces an air of rarity (tiny pieces of chocolates are displayed in a glass case as if they were jewelry); the packaging which has an air of elegance; the various colors of the chocolates; and the distinct shapes of the chocolates, each of them being slightly different.

In the case of Meiji, although their products are not designed to satisfy our sense of sight like GODIVA products do, they still provide plenty of satisfaction through our sense of taste, which is a basic benefit that food provides.

As for Ferrari, the low body of the car with a streamlined shape and the image of the prancing horse, which is Ferrari's symbolic emblem, satisfy our sense of sight. Furthermore, the distinct high-pitched sound of the engine stimulates our sense of hearing and the vibration from the engine compartment which can be felt through the seat and steering wheel stimulates our sense of touch, adding extra elements of satisfaction.

In the case of Toyota, in contrast to Ferrari, it is the silence we experience when we drive the car that satisfies our sense of hearing. In addition, the comfortable seats satisfy our sense of touch.

As you can see, all the brands have been successful in achieving the purpose of Sense marketing regardless of product category or brand rank.

For these reasons, I believe that the regression coefficient $\beta_{\mathrm{S}}$ will show a significant positive correlation for all brands. Thus, 
the following hypothesis should hold true.

[Hypothesis 1]"Sense" will have a direct positive effect on purchase intention for all subject brands.

\subsection{Hypothesis of Feel}

Feel marketing involves providing emotions such as positive feelings, joy, and pride through Experience Providers (hereinafter referred to as ExPro), which is shown in Table 8.

I believe that GODIVA has been successful in providing customers with a sense of pride or excitement as luxury brands through product and shop designs, which are described in the previous section.

In the case of Meiji, the brand has gained wide recognition through many years of promotional activities. Furthermore, although there has been a succession of scandals in the news in recent years involving food manufacturers, I do not recall Meiji being involved in any major incidents. For these reasons, I believe that Meiji has been successful in providing customers with a positive feeling by ensuring them safety and security through their brand logo, which has been placed on the packaging.

I believe that Ferrari, just as GODIVA, has been successful in providing customers with a sense of pride or excitement as luxury brands through the use of ExPro such as the distinct body of the car and emblem, which I described in the previous section.

I believe that Toyota, despite being a mass brand, has earned an exceptionally good reputation as one of Japan's most technologically advanced brands. Therefore, I believe that the company has been successful in providing a sense of joy and pride by ensuring safe, secure, and comfortable driving through their logo.

Based on the above, I believe that all the brands have been able to achieve the purpose of Feel marketing regardless of product category or brand rank.

For these reasons, I believe that the regression coefficient $\beta_{F}$ will show a significant positive correlation for all brands. Thus, the following hypothesis should hold true.

[Hypothesis 2]"Feel" will have a direct positive effect on purchase intention for all subject brands.

Table 8. Experience Provider

\begin{tabular}{l|l}
\hline ExPro & Concrete Example \\
\hline Communication & $\begin{array}{l}\text { Advertisement, Catalog, Brochure or newsletters, } \\
\text { Annual report, Brand PR campaign }\end{array}$ \\
Identity & $\begin{array}{l}\text { Naming, Logo and emblem } \\
\text { Product }\end{array}$ \\
Co-branding & $\begin{array}{l}\text { Event marketing, Sponsorship, Product placement } \\
\text { Space of building, office and factory, Selling space, }\end{array}$ \\
Space & Public space, Trading space \\
Website & Sales staff, CEO, Service provider, Stakeholder \\
\hline
\end{tabular}

Source: Nagasawa $\cdot$ Otsu [21]

\subsection{Hypothesis of Think}

The purpose of Think marketing described in Table 7 can be described as "stimulating the intellectual curiosity of consumers." I believe that getting consumers to want to know more about the brand is essential for a luxury brand to be successful. Therefore, I believe that both GODIVA and Ferrari, both of which have gained their status as luxury brands, have achieved the purpose of Think marketing.

As for car brands, I believe that customers have a high involvement to the products themselves, and it can be inferred that this high involvement has developed intellectual curiosity among consumers. Therefore, I believe that Toyota, which is a mass brand, has also achieved the purpose of Think marketing.

As for Meiji, since they belong to the category of food, I believe that customers have a low involvement to the brand. In addition, since they are a mass brand, I believe that there is a weak correlation with intellectual curiosity.

For these reasons, I believe that the regression coefficient $\beta_{\mathrm{T}}$ will show a significant positive correlation for only GODIVA, Ferrari, and Toyota. Thus, the following hypothesis should hold true.

[Hypothesis 3]"Think" will have a direct positive effect on purchase intention for GODIVA, Ferrari, and Toyota only.

\subsection{Hypothesis of Act}

Based on the description in Table 7, I believe that Act is an experience type that is closely connected with conspicuousness. In other words, it can be interpreted that the purpose of Act marketing is to satisfy the conspicuous desires of consumers. As I stated in Section 2.1, conspicuousness has been believed to be a typical motive for the consumption of luxury brands since the dawn of the era for research on consumer behavior towards luxury brands. Such trends are still very noticeable today among consumers.

For these reasons, both GODIVA and Ferrari, which are luxury brands, have achieved the purpose of Act marketing.

As for cars, the products themselves have a strong correlation with conspicuousness and therefore cars, despite being mass brands, have achieved the purpose of Act marketing. In other words, conspicuousness, contrary to Rae [7] and Veblen [8]'s arguments, is not necessarily a motive for consumption for luxury brands in particular. For products like cars, in which customers have a high involvement to the brand and are visible in public, satisfying the conspicuous desires of consumers is a direct contributing factor in the development of consumption motives, even for mass brands.

As for Meiji, since they belong to the category of food, I believe that customers have a low involvement to the brand. In addition, since they are a mass brand, there is a weak correlation with conspicuousness.

For these reasons, I believe that the regression coefficient $\beta_{\mathrm{A}}$ will show a significant positive correlation for only GODIVA, Ferrari, and Toyota. Thus, the following hypothesis should hold true.

[Hypothesis 4]"Act" will have a direct positive effect on purchase intention for GODIVA, Ferrari, and Toyota only. 


\subsection{Hypothesis of Relate}

Keller [22] states that for the top brands, it is the consumers who have a strong emotional attachment or passion towards the brand who end up being the preachers and missionaries for the brands, tell others about their faith in the brand, and make the brand recognized through word of mouth. This is similar to the purpose of Relate marketing which is explained in Table 7.

In other words, luxury brands, which are the top brands, make an attempt to distinguish themselves from mass brands while also earning customer loyalty by providing customers with Relate. For companies, achieving the purpose of Relate marketing can be described as the most difficult aspect as well as the most important mission in coming up with luxury brand strategies. Relate can be described as the experience type that reveals a luxury brand's true value.

For these reasons, I believe that GODIVA and Ferrari, both of which have gained their status as luxury brands, have achieved the purpose of Relate marketing.

On the other hand, it would be hard to imagine that Meiji and Toyota, which are mass brands, have attracted customers who can be described as what Keller [22] describes as followers. Therefore, these brands do not fall under the category of luxury brands, which are the top brands.

For these reasons, I believe that the regression coefficient $\beta_{R}$ will show a significant positive correlation for only GODIVA and Ferrari. Thus, the following hypothesis should hold true.

[Hypothesis 5]"Relate" will have a direct positive effect on purchase intentions for GODIVA and Ferrari only.

\section{Result of Analysis}

After performing credibility analysis on the questionnaires (Table 6), the results showed that, as it is shown in Table 9, there was a high level of trust for all dimensions. Therefore, I performed a multiple regression analysis without making any adjustments. The results are shown in Table 10. I will discuss these results in order.

Table 9. Cronbach's Coefficient Alpha

\begin{tabular}{llllll}
\hline \multirow{2}{*}{ Brands } & \multicolumn{6}{l}{ Experience types } & & & \\
\cline { 2 - 6 } & SENSE & FEEL & THINK & ACT & RELATE \\
\hline GODIVA & .827 & .879 & .815 & .825 & .751 \\
MEIJI & .835 & .861 & .801 & .815 & .785 \\
FERRARI & .847 & .889 & .820 & .827 & .827 \\
TOYOTA & .866 & .898 & .801 & .770 & .755 \\
\hline
\end{tabular}

Table 10. Result of multiple regression analysis about Experiential Marketing

\begin{tabular}{|c|c|c|c|c|c|c|}
\hline \multirow{2}{*}{ Brands } & \multicolumn{5}{|c|}{ Standard Partial Regression Coefficient } & \multirow{2}{*}{$\begin{array}{l}\text { Adjusted } \\
\mathbf{R}^{2}\end{array}$} \\
\hline & $\beta_{\mathrm{s}}$ & $\beta_{F}$ & $\beta_{\mathrm{T}}$ & $\boldsymbol{\beta}_{\mathrm{A}}$ & $\beta_{R}$ & \\
\hline & .148 & .40 & -.16 & .036 & $.213^{* * *}$ & $.365^{* * *}$ \\
\hline ME & $.247^{* * *}$ & .29 & $-.248^{* * *}$ & .106 & .112 & $.246^{* * *}$ \\
\hline $\mathrm{FEI}$ & $.160^{* *}$ & $.271^{* * *}$ & -.047 & $.175^{*}$ & $212^{* * *}$ & $.469^{* * *}$ \\
\hline TOYOTA & $298^{* * *}$ & $.325^{* * *}$ & $-.229^{* * *}$ & $.185^{* *}$ & .088 & $.358^{* * *}$ \\
\hline
\end{tabular}

Note: Significance Level $\quad * \mathrm{p}<.05, \quad * * \mathrm{p}<.01, \quad * * * \mathrm{p}<.001$

\section{Consideration}

The results of the hypothesis testing are shown in Table 11. I will discuss these results in order.

Table 11. Result of Hypothesis Testing

\begin{tabular}{|c|c|c|}
\hline \multicolumn{2}{|c|}{ Hypotheses } & \multirow{4}{*}{$\begin{array}{l}\text { Verification } \\
\text { Results } \\
\text { Supports } \\
\text { hypothesis } \\
\text { Supports } \\
\text { hypothesis }\end{array}$} \\
\hline H1. & "Sense" will have a direct positive effect on & \\
\hline $\mathrm{H} 2$. & $\begin{array}{l}\text { purchase intention for all subject brands. } \\
\text { "Feel" will have a direct positive effect on }\end{array}$ & \\
\hline & $\begin{array}{l}\text { purchase intention for all subject brands. } \\
\text { "Think" will have a direct positive effect on }\end{array}$ & \\
\hline H3. & $\begin{array}{l}\text { purchase intentions for GODIVA, Ferrari, } \\
\text { and Toyota only. }\end{array}$ & $\begin{array}{l}\text { Does not support } \\
\text { hypothesis }\end{array}$ \\
\hline $\mathrm{H} 4$. & $\begin{array}{l}\text { "Act" will have a direct positive effect on } \\
\text { purchase intentions for GODIVA, Ferrari, } \\
\text { and Toyota only. }\end{array}$ & $\begin{array}{l}\text { Partially supports } \\
\text { hypothesis }\end{array}$ \\
\hline H5. & $\begin{array}{l}\text { "Relate" will have a direct positive effect on } \\
\text { purchase intentions for GODIVA and } \\
\text { Ferrari only. }\end{array}$ & $\begin{array}{l}\text { Supports } \\
\text { hypothesis }\end{array}$ \\
\hline
\end{tabular}

\subsection{Consideration of Hypothesis No.1 Sense}

The regression coefficient $\beta_{\mathrm{S}}$ showed a significant positive correlation for all subject brands. This result supports Hypothesis No. 1.

As I stated in the hypothesis, the purpose of Sense marketing --providing a sense of joy or excitement by stimulating the five senses-- was achieved for all brands, regardless of product category or brand rank. Furthermore, the results suggested the possibility that Sense has a direct positive effect on purchase intention.

In other words, the results suggested that providing the Sense experience is something that a brand must achieve and that providing this experience is not enough for both food and car luxury brands to distinguish themselves from mass brands.

\subsection{Consideration of Hypothesis No.2 Feel}

The regression coefficient $\beta_{\mathrm{F}}$ showed a significant positive correlation for all subject brands. This result supports Hypothesis No. 2.

As I stated in the hypothesis, the purpose of Feel marketing --stimulating the emotions through advertisements and products-- was achieved for all brands regardless of product category or brand rank. Furthermore, the results suggested the possibility that Feel has a direct positive effect on purchase intention.

Therefore, the results suggested that providing the Feel experience, just as Sense, is something that a brand must achieve and providing this experience is not enough for both food and car luxury brands to distinguish themselves from mass brands.

\subsection{Consideration of Hypothesis No.3 Think}

The regression coefficient $\beta_{\mathrm{T}}$ showed a significant negative correlation for GODIVA, Meiji, and Toyota and a negative figure for Ferrari (although it was not statistically significant). These results do not support Hypothesis No. 3. 
Since the results were drastically different from what I predicted, I conducted the following multiple regression analysis in order to determine the causes.

I assigned the Purchase Intentions (hereinafter referred to as PI) for the four brands being examined in this study as the explained variables and assigned $\mathrm{X}_{\mathrm{Q} 7}, \mathrm{X}_{\mathrm{Q} 8}, \mathrm{X}_{\mathrm{Q} 9}$ as the explanatory variables for Q7, Q8, and Q9 in order in Table 6. I then assigned $\beta_{\mathrm{Q} 7}, \beta_{\mathrm{Q} 8}$, and $\beta_{\mathrm{Q} 9}$ in order as standard partial regression coefficients for the explanatory variables and $\beta_{0}$ as a constant term to complete the following multiple regression model equation (2). The result of the multiple regression analysis I performed with this method is shown in Table 12.

$\mathrm{PI}=\beta_{\mathrm{Q} 7} \cdot \mathrm{X}_{\mathrm{Q} 7}+\beta_{\mathrm{Q} 8} \cdot \mathrm{X}_{\mathrm{Q} 8}+\beta_{\mathrm{Q} 9} \cdot \mathrm{X}_{\mathrm{Q} 9}+\beta_{0}$

Table 12. Result of multiple regression analysis about Think

\begin{tabular}{lllll}
\hline \multirow{3}{*}{ Brands } & \multicolumn{3}{l}{$\begin{array}{l}\text { Standard Partial } \\
\text { Regression Coefficient }\end{array}$} & \multirow{2}{*}{ Adjusted $\mathbf{R}^{2}$} \\
\cline { 2 - 4 } & $\boldsymbol{\beta}_{\mathbf{Q} 7}$ & $\boldsymbol{\beta}_{\mathbf{Q} 8}$ & $\boldsymbol{\beta}_{\mathbf{Q} 9}$ & \\
\hline GODIVA & $.250^{* * *}$ & $.313^{* * *}$ & $-.165^{* *}$ & $.175^{* * *}$ \\
MEIJI & $.132^{*}$ & $.301^{* * *}$ & $-.195^{* * *}$ & $.096^{* * *}$ \\
FERRARI & $.147^{* *}$ & $.407^{* * *}$ & .051 & $.294^{* * *}$ \\
TOYOTA & $.122^{*}$ & $.351^{* * *}$ & -.055 & $.161^{* * *}$ \\
\hline
\end{tabular}

Note: Significance Level $\quad * \mathrm{p}<.05, \quad * * \mathrm{p}<.01, * * * \mathrm{p}<.001$

Based on these results, I believe the above results are attributable to Q9 in Table 6: "X has provocative implications." A possible reason for this may be that people interpreted the term "provocative" in the question as having a negative connotation. As you can see in Table 12, the regression coefficient $\beta_{\mathrm{Q} 9}$ showed a significant negative correlation for both GODIVA and Meiji. It is true that using the term provocative to describe these brands is inappropriate. The term, in the way Schmitt [1] uses it, does not have a negative connotation. In consideration of this, I need to reconsider how the question is worded.

As for why the regression coefficient $\beta_{\mathrm{Q} 9}$ showed a positive figure for only Ferrari, I believe this was because many people interpreted the term provocative as having a positive connotation for Ferrari.

Furthermore, since regression coefficients $\beta_{\mathrm{Q} 7}$ and $\beta_{\mathrm{Q} 8}$ are statistically significant for all brands, I came to the conclusion that providing an explanation for differences in results between product categories and brand ranks from the analyses on Think in this paper is difficult.

\subsection{Consideration of Hypothesis No. 4 Act}

Although standard partial regression coefficient $\beta_{\mathrm{A}}$ showed a significant positive correlation for Ferrari and Toyota, it was not statistically significant for GODIVA. These results partially support Hypothesis No. 4.

As I stated earlier, I believe that Act is an experience type that is related to conspicuousness and therefore predicted that there would be a significant positive correlation for luxury brands, even in the food category. However, the results suggested the possibility that Act has a direct positive effect on purchase intention for the product category of cars only, regardless of brand ranks.

In other words, the results suggest that the effect that Act has on purchase intention is more noticeable between product categories than it is between brand ranks and that conspicuousness, which Rae [7] and Veblen [8] pointed out as being a motive for the consumption of luxury brands, does not necessarily apply to luxury brands in particular.

This is because even if conspicuousness were a purchase motive of luxury brands in particular, regression coefficient $\beta_{\mathrm{A}}$ would show a significant positive correlation for only GODIVA and Ferrari. Even if it was determined that there was no significant positive correlation for GODIVA because their Relate marketing strategies were inadequate, the results for Toyota, which is a mass brand in the category of cars, showed a significant positive correlation. Such results are not consistent with Rae [7]'s or Veblen [8]'s claims. In considering the possibility that the definition of luxury changes as time passes, it can be argued that although it cannot be disputed that during the 19th century, conspicuousness may have been a motive for the consumption of luxury brands, which is a claim that Rae [7] and Veblen [8] made, this notion does not necessarily apply today.

\subsection{Consideration of Hypothesis No. 5 Relate}

The regression coefficient $\beta_{R}$ showed a significant positive correlation for only GODIVA and Ferrari. This result supports Hypothesis No. 5.

In other words, the results suggest the possibility that luxury brands that have earned customer loyalty have made an attempt to distinguish themselves from mass brands by achieving the purpose of Relate marketing, regardless of product category. This suggests that providing the Relate experience is a common strategy that is shared by food and car luxury brands.

In the case of GODIVA, roughly $75 \%$ of people who purchase their products buy them as gifts [23], 30\% of the company's sales occur around the time of Valentine's Day [24]. Consumers are choosing GODIVA products as gifts, for Valentine's Day in particular, and purchase them to express their feelings towards significant others. This is an indication that people want to build relationships through GODIVA products. GODIVA has become a brand that has earned customer loyalty for a major traditional event in Valentine's Day, which is an indication that GODIVA has succeeded in producing emotions that go beyond an attachment towards the products and are similar to devotion.

As for Meiji, it is probably a rare occurrence for customers to make their purchases as gifts, as is the case with GODIVA products. I would think that, in general, very few consumers make their purchases with a strong emotional attachment towards the brand.

Ferrari has owners' clubs worldwide which are operated by the company. Through tours and various other events, members are able to have strong connections with other club members [25]. The brand has succeeded in making people want to have a connection with other consumers, which fits the description provided in Table 7. 
As for Toyota, although customers have a high involvement to the brand, it is hard to imagine that they have customers who can be described as followers like the ones for Ferrari. I could not find any owners clubs that are operated by Toyota like the ones Ferrari has.

These results suggest that luxury brands have successfully adopted Relate marketing strategies through a variety of methods according to the product category and have made an attempt to distinguish themselves from mass brands.

\section{Conclusion}

The objectives of this paper were to empirically demonstrate that luxury brand strategies can be applied to food brands as well as the aspects in which luxury brands have attempted to distinguish themselves from mass brands to allow them to gain their status as luxury brands. In order to achieve these things, I examined GODIVA as a luxury food brand that has enjoyed success in Japan. In addition, in order to clarify the differences between brand ranks, I examined Meiji as a mass food brand. Furthermore, in order to perform comparative analyses, I chose the product category of cars, which has different characteristics from food. In particular, I examined Ferrari, a luxury car brand, and Toyota, a mass brand in the category of cars.

I performed a multiple regression analysis based on the concept of experiences, which was proposed by Schmitt [1], as an analytical perspective. The results suggested that distinguishing themselves from mass brands by using the experience types of Sense and Feel is difficult for GODIVA, just as it is for Ferrari and that providing these two experiences is accepted by consumers as being something mass brands, not just luxury brands, must achieve at the very least.

The results also suggested that GODIVA, just as Ferrari, has set itself apart from mass brands by providing the Relate experience.

They also suggest through assessments of the Act experience that conspicuousness, which has been believed to be a typical motive for the consumption of luxury brands since Rae [7] and Veblen [8] made the claim during the 19th century, does not necessarily apply to luxury brands in particular. Although this was not one of my objectives when the study began, it was a meaningful discovery. The results of the empirical comparative analyses for this study suggest the following:

1) Providing customers with satisfaction through the five senses and positive feelings by taking advantage of advertisements, products, and store designs is something a brand must achieve at the very least, regardless of brand ranks, for the product categories of food and cars, and providing this value alone will not be enough for luxury brands to distinguish themselves from mass brands.

2) Both food and car luxury brands make an attempt to distinguish themselves from mass brands by producing emotions that will make consumers want to have an active connection with other consumers or voluntarily recommend the brand to others.
3) Although it cannot be disputed that during the 19th century, conspicuousness may have been a motive for the consumption of luxury brands, which is a claim that Rae [7] and Veblen [8] made, that notion does not necessarily apply today.

Through these findings, I believe that I was able to achieve some positive results in this study. However, the following limitations and future challenges also arose.

In this paper, I examined four brands in the product categories of food and cars. However, the results for this study are not enough to draw conclusions about the characteristics of those product categories. In other words, you would be hard pressed to say that the observations that were made about GODIVA hold true for all luxury food brands, and conclusions cannot be drawn for the product category as a whole. The same can be said about Meiji, Ferrari, and Toyota. Therefore, the results of this study merely suggest possible characteristics of the product categories that the subject brands belong to.

Furthermore, motives for the consumption of luxury brands are deeply connected with psychological factors. Therefore, the personality traits of consumers must be considered. In this study, analyses were performed without categorizing the personalities of the participants. For this reason, it is impossible to tell whether differences in personalities have an effect on the results.

Furthermore, this study demonstrated the importance of the Relate experience in coming up with luxury brand strategies. However, in order to identify the types of promotional activities that GODIVA and Ferrari are actually carrying out to provide the Relate experience, exhaustive tests through case studies need to be carried out. My goal is to tackle these challenges in the future.

\section{Note}

1. The definition of luxury tends to vary depending on the perspective, and there is no single definition. The definition of luxury for this paper will be provided in Section 2.3.

2. Terasaki [11]'s translation.

3. I added trick questions to the questionnaires such as: "Please choose '1. I strongly disagree' for this question" or "Please choose '7. I strongly agree' for this question."

\section{References}

[1] Schmitt, B.H.(1999)Experimental Marketing: How to Get C ustomers to Sense, Feel, Think, Act, Relate, Free Press

[2] Saito, Michitaka.(2008)"Buying Behavior Model for Luxury Brands"Mita Business Review(Keio University), Vol. 51, No. 4, pp.93-106.

[3] LVMH Moët Hennessy Louis Vuitton Japan "LVMH's Profi le and Activities - Growth Strategy" $<$ http://www.lvmh.co.j p/group/grow.html $>$ (Accessed 11 September 2014)

[4] "Luxury Chocolate Brand GODIVA to Increase Number of Outlets in Japan to 300 within Next Five Years, Plans to O pen Outlet in Tottori by End of Year to Achieve Goal of Having Outlet in Every Prefecture" August 22, 2014, p. 14 
[5] Terasaki, Shinichiro.(2013)“The Birth of Luxury Strategy, and Re-examination of the Concept of Luxury Brands"Th e Bulletin of Waseda University Graduate School of Com merce, Vol. 77, pp.139-161

[6] Ipsos(2011)"World luxury tracking" $<$ http://www.luxuryoutlo ok2011.com/luxury-tracking/>(Accessed 9 March 2014) , A uthors have not read the original. Cited from Terasaki, S hinichiro.(2013)“The Management of Rarity in Luxury Br ands: An Exploration on Information-based Rarity"The Bu lletin of Waseda University Graduate School of Commerc e, Vol. 78, pp.87-109

[7] Rae, J (1834) Statement of Some New Principles on the Subject of Political Economy, Exposing the Fallacies of $t$ he System of Free Trade and of Some Other Doctrines Maintained in the 'Wealth of Nations, Boston: Hilliard, G ray, \& Co.

[8] Veblen, T.B.(1899)"The Theory of the Leisure Class: An Economic Study in the Evolution of Institutions"Macmilla $\mathrm{n}$

[9] Leibenstein, H(1950)"Bandwagon, Snob, and Veblen Effec ts in the Theory of Consumers' Demand"The Quarterly J ournal of Economics, Vol. 64, No. 2 (May, 1950), pp.183 $-207$

[10] Vigneron, F \& Lester W. Johnson(1999)“A Review and C onceptual Framework of Prestige Seeking Consumer Beha vior"Academy of Marketing Science Review, pp.1-15.

[11] Terasaki, Shinichiro.(2013)"The Empirical Study on the Per ceived Values in Luxury Brands" The Journal on Business and Economics, Waseda University Graduate School of Co mmerce, Vol. 105, pp.39-51

[12] Kapferer, J.N.(1998)"Why are we seduced by luxury bran ds?”Journal of Brand Management, vol.6,no.1, pp.44-49

[13] Steele, V.(2008)“LECTURE Luxury: Conspicuous Extrava gance to Sensory Pleasure"DRESSTUDY, Kyoto Costume Institute, Vol. 54, pp.21-23

[14] Catry, B.(2003)“"The Great Pretenders: The Magic of Lux ury Goods," Business Strategy Review, Vol. 14 (3), pp. 1 $0-17$.
[15] TOP NEWS(2014)"Ferrari announced its financial result for the fiscal year ended 2013, achieved increase in income a nd profit" $<$ http://www.topnews.jp/2014/02/19/auto/103766.h tml $>$ (Accessed 17 September 2014)

[16] The Nikkei "GOVIDA finish a contract with KATAOKA a nd then makes all stores in Japan directly-managed"〈http:// www.nikkei.com/article/DGXNASDZ2700J_X20C14A6EAF 000/> (Accessed 17 October 2014)

[17] Godiva Japan, Inc. GOVIVA Boutique - Shop List in Tok yo」<http://www.godiva.co.jp/boutique/boutique_tokyo.html $>$ (Accessed 31 August 2014)

[18] "Luxury Chocolate Brand GODIVA to Increase Number of Outlets in Japan to 300 within Next Five Years, Plans to O pen Outlet in Tottori by End of Year to Achieve Goal of Having Outlet in Every Prefecture" August 22, 2014, p. 14

[19] Vaughn, Richard(1980)“How Advertising Works: A Planni ng Model"Journal of Advertising Research, 20(5), pp.27-3 3

[20] The Nikkei edited (2013)"The 2014 Market Share in Japan” Nikkei Publishing Inc.

[21] Nagasawa, Shinya \& Otsu, Shinichi(2010)“A Study on Ex periential Marketing -Focusing on Strategic Experiential Modules-"Waseda Bulletin of International Management, NO.41, pp.69-77

[22] Keller, Kevin Lane(1997)Strategic Brand Management: Buil ding, Measuring, and Managing Brand Equity, Prentice Hal 1 College

[23] Nikkei Sangyo Newspaper "GODIVA Makes The Sales in J apan doubled within 5 years - Planning to Open 10 New Stores This Year, Expanding Its Stores to Hotels and so on" 21 September 2006

[24] PANADERIA“GOVIVA 2014 Valentine Collection" $<\mathrm{http}: / / \mathrm{w}$ ww.panaderia.co.jp/event_report/godiva_2014vt/index.html> (Accessed 5 October 2014)

[25] Ferrari Club of Japan(2014)“Welcome-Ferrari Club of Japa n" <http://www.ferrari-club-of-japan.jp/youkoso.html>(Acces sed 5 October 2014) 